\title{
Isn't It Time to Stop Talking About Colonoscopy Quality and Start Doing Something About It?
}

\author{
Swati G. Patel · Dennis J. Ahnen
}

Published online: 24 August 2011

(C) Springer Science+Business Media, LLC (Outside the USA) 2011

Colonoscopy is central to one of the great success stories of the war on cancer. Although colorectal cancer (CRC) is still the second leading cause of cancer death in the United States, both the incidence and mortality has been declining by $2-3 \%$ per year for the last 15 years. This decline has been largely attributed to increasing rates of CRC screening. Although guidelines list other screening options (stool tests/imaging/flexible sigmoidoscopy) colonoscopy has become the dominant CRC screening test in the US while fecal testing has declined slowly, and flexible sigmoidoscopy has declined markedly over the last decade [1].

Colonoscopy is widely viewed in the US as the single best test for both detection and removal of pre-cancerous lesions. The efficacy of colonoscopic polypectomy was initially highlighted by the National Polyp Study (NPS), which estimated a 76-90\% reduction in incidence of colorectal cancer after polyp removal [2]. Subsequent studies [3], which often have not shown as robust a CRC risk reduction as the NPS, have highlighted the importance of the quality of colonoscopy as a critical element in its efficacy.

There is compelling evidence that colonoscopy quality is highly variable [4] and guidelines for a high-quality colonoscopy have been published [5], but in the end, quality needs to be assessed by whether a test accomplishes its primary goal. In the case of colonoscopy, directly measuring whether a colonoscopy has prevented a CRC is not feasible in the short term. Instead, more measurable surrogates of quality such as cecal intubation rates,

S. G. Patel · D. J. Ahnen ( $\square)$

Department of Medicine, Division of Gastroenterology,

Denver VA Medical Center and University of Colorado

School of Medicine, Denver, CO, USA

e-mail: dennis.ahnen@ucdenver.edu withdrawal times, and particularly adenoma detection rates (ADR) have been used as quality measures. Kaminski et al. found that ADR appeared to be an acceptable surrogate for real colonoscopy quality as it was an independent predictor of the risk of interval colorectal cancer [6]. Numerous studies have demonstrated marked (twofold to sixfold) variability in ADRs among endoscopists working in the same endoscopy unit [4]. Although some of this variability might be due to patient factors such as age, gender, or adequacy of bowel preparation, individual endoscopists appear to be the single most predictive factor in adenoma detection [7], implying that the efficacy of colonoscopy is highly dependent on the individual skill of the endoscopist. To compound matters, Brenner [8] and Lakoff [9] presented data from Germany and Canada that showed that while colonoscopy does decrease the rate of distal CRCs by approximately $67-79 \%$, it was not at all protective for proximal colon cancers, suggesting that there is a substantial need for improvement in colonoscopy quality by all endoscopists.

The variability in colonoscopy quality among providers and the dubious utility of colonoscopy in preventing rightsided colon cancers have called into question the overall efficacy of colonoscopy as it is used today and would seem to be a clear mandate for endoscopists and professional organizations to critically examine colonoscopist performance and address areas in need of improvement. Is it possible to identify provider characteristics that are predictive of quality procedures? If so, can we incorporate these findings into endoscopic training, continuing medical education and ultimately ongoing quality assurance programs? Any such efforts are dependent, in part, on an understanding of the relationships between endoscopist characteristics and quality outcomes and there is growing literature examining one aspect of this relationship-the 
Table 1 Interval CRC rates after a negative colonoscopy by specialty training

\begin{tabular}{|c|c|c|c|c|c|c|c|}
\hline \multirow[t]{2}{*}{ Author (year) } & \multirow[t]{2}{*}{ Database } & \multirow[t]{2}{*}{$\begin{array}{l}\text { Colonoscopies } \\
\text { performed, } n\end{array}$} & \multirow[t]{2}{*}{$\begin{array}{l}\text { Interval } \\
\text { CRCs, } n\end{array}$} & \multirow[t]{2}{*}{$\begin{array}{l}\text { Overall miss } \\
\text { rate }(\%)\end{array}$} & \multicolumn{3}{|c|}{$\begin{array}{l}\text { Miss rate }(\%) \text { by specialty } \\
\text { Odds ratio }(95 \% \mathrm{CI})\end{array}$} \\
\hline & & & & & GI & Surgery & Other \\
\hline Rex et al. (1997) & $\begin{array}{l}20 \text { Indiana hospitals } \\
\quad(1988-1993)\end{array}$ & 941 & 47 & $5 \%$ & $\begin{array}{l}2.7 \% \\
1\end{array}$ & $\begin{array}{l}13 \%^{\mathrm{a}} \\
5.36(2.94-9.77)\end{array}$ & $\begin{array}{l}13 \%^{\mathrm{a}} \\
5.36(2.94-9.77)\end{array}$ \\
\hline Singh et al. (2010) & Manitoba (1989-2006) & 45,695 & 137 & $0.30 \%$ & $\begin{array}{l}0.14 \% \\
1\end{array}$ & $\begin{array}{l}0.32 \% \\
3.38(1.83-6.24)^{\mathrm{b}} \\
1.78(1.27-2.5)^{\mathrm{c}}\end{array}$ & $\begin{array}{l}0.39 \% \\
2.25(1.35-3.76)^{\mathrm{d}} \\
3.01(1.42-6.37)^{\mathrm{e}}\end{array}$ \\
\hline Rabeneck et al. (2010) & Ontario (1992-1997) & 110,402 & 1,596 & $1.4 \%$ & 1 & $\begin{array}{l}\mathrm{NR} \\
1.39(1.16-1.67)^{\mathrm{f}}\end{array}$ & $\begin{array}{l}\text { NR } \\
1.28(1.08-1.51)^{\mathrm{f}}\end{array}$ \\
\hline Kaminski et al. (2010) & Poland (2000-2004) & 45,026 & 42 & $0.093 \%$ & $0.088 \%$ & $\begin{array}{l}0.105 \% \\
\text { NR }\end{array}$ & $\begin{array}{l}0.086 \% \\
\text { NR }\end{array}$ \\
\hline Baxter et al. (2011) & Ontario (2000-2005) & 14,064 & 1,260 & $8.9 \%$ & $\begin{array}{l}9.0 \% \\
1\end{array}$ & $\begin{array}{l}8.2 \% \\
1.23(0.96-1.57)^{\mathrm{g}} \\
0.96(0.73-1.25)^{\mathrm{h}}\end{array}$ & $\begin{array}{l}12.7 \% \\
1.87(1.34-2.6)^{\mathrm{g}} \\
1.67(1.13-2.46)^{\mathrm{h}}\end{array}$ \\
\hline Singh et al. (2011) & $\begin{array}{l}\text { US Medicare } \\
\quad(1996-2005)\end{array}$ & 200,857 & 4,620 & $2.3 \%$ & $\begin{array}{l}1.94 \% \\
1\end{array}$ & $\begin{array}{l}2.64 \% \\
1.3(1.15-1.48)\end{array}$ & $\begin{array}{l}2.89 \% \\
1.17(1.0-1.37)^{\mathrm{i}} \\
1.32(1.09-1.6)^{\mathrm{j}}\end{array}$ \\
\hline
\end{tabular}

$N R$ not reported

${ }^{\mathrm{a}}$ Did not differentiate between surgeons and other providers; ${ }^{\mathrm{b}}$ rural surgeons; ${ }^{\mathrm{c}}$ urban surgeons; ${ }^{\mathrm{d}}$ internists; ${ }^{\mathrm{e}}$ family practice; ${ }^{\mathrm{f}}$ hospital setting;

${ }^{\mathrm{g}}$ proximal CRC; ${ }^{\mathrm{h}}$ distal CRC; ${ }^{\mathrm{i}}$ generalist; ${ }^{\mathrm{j}}$ other/unknown

training and ongoing experience of the endoscopist (Table 1).

Rex et al. [10] initially suggested the possibility that endoscopist training was an important variable in colonoscopy quality and outcome when he reviewed colonoscopy and barium enema records from the previous 3 years in 2,193 consecutive patients with newly diagnosed CRC. They found that the sensitivity of colonoscopy in detecting CRC was significantly better for colonoscopies performed by gastroenterologists than those done by non-gastroenterologists (OR for missed CRC 5.36; 95\% CI, 2.94-9.77). Singh et al. [11] also found that colonoscopy by a nongastroenterologist was an independent predictor of colon cancer after a negative colonoscopy. In this retrospective review of the Manitoba billing database, $79 \%$ of negative colonoscopies were performed by non-gastroenterologists and yet $90 \%$ of early CRCs after negative colonoscopy were found in patients who had a colonoscopy performed by a non-gastroenterologist. Similarly, Rabeneck et al. [12] found that patients who had colonoscopy performed in the hospital setting by a non-gastroenterologist in Ontario had a significantly higher risk of developing colon cancer than those who had colonoscopy performed by a gastroenterologist (OR 1.28-1.39). Similarly, a review of the Ontario Cancer Registry by Baxter et al. [13] found that there was a significantly higher rate of post-colonoscopy colorectal cancer in patients who underwent colonoscopy by a nongastroenterologist and non-surgeon but no differences between surgeons and gastroenterologists. In contrast, Kaminski et al. [6] found no difference in the interval cancer rates among Polish gastroenterologists, surgeons, and internists/others. Screening colonoscopy is more widely performed in the US than in Europe or Canada and until now there has been little data about interval CRC rates in the US (outside of Indiana 910).

In this issue of DDS, Singh et al. [14] report interval CRC rates from 1995 to 2006 using a 5\% national sample from the US Medicare Claims Database. They analyzed the relationship of interval CRC rates, defined as those that were identified between 1 and 10 years after a negative colonoscopy (one in which no biopsy, polypectomy, or fulguration was performed), with characteristics of the patients (age, sex, race, place and type of residence, income, and education level), the procedure (location in hospital, ambulatory center or office) and of the physician (specialty, volume of colonoscopies performed on Medicare patients). The overall incidence of interval CRCs was 1.8 per 1,000 years of follow-up. Higher rates were found in men and in patients over 85 years and a highly significant twofold range of interval CRC rates was observed across regions of the country.

One of the most interesting findings of the Singh et al. [14] paper is that physician specialty and colonoscopy volume were significantly related to interval CRC rates. Among this sample of Medicare enrollees, 55\% of the colonoscopies were performed by gastroenterologists, $28 \%$ 
by surgeons, $11 \%$ by generalists, and $6 \%$ by other or unknown specialties. There was a significantly lower interval CRC rate after colonoscopies performed by gastroenterologists $(1.9 \%$ at 10-year follow-up) compared to those performed by the other specialists (2.6-3.1\%). Furthermore, endoscopists in the lowest quartile of colonoscopy volume had a significantly higher interval cancer rate ( $2.8 \%$ compared to $1.8 \%$ in the lowest volume quartile), but this relationship was only found in the non-gastroenterologist groups; there was no relationship between colonoscopy volume and interval CRC rates among gastroenterologists.

The study by Singh et al. [14] may well be an underestimation of the magnitude of the problem of interval cancers because about $30 \%$ of interval cancers are estimated to arise from incomplete polypectomies [15] and this study excluded colonoscopies with polypectomy. Nonetheless, there is now substantial data, including from the US that colonoscopy quality varies by specialty training in both a statistically and clinically meaningful manner with gastroenterologists typically having the lowest overall interval CRC rates. This issue has been discussed repeatedly [4, 6-15]; it is time for the medical community to act on this information.

It seems very likely that the differences in colonoscopy quality by specialty are a reflection of differences in training and ongoing experience. There are major differences in the expectations for training of gastroenterologists and colorectal surgeons compared to other specialists. The current Accreditation Council of Graduate Medical Education (ACGME) requirements for Gastroenterology and the American Board of Colorectal Surgeons [16] requires all fellows to complete a minimum of 140 supervised colonoscopies including at least 20 polypectomies during their training and training programs then must "evaluate and measure competency" in colonoscopy. Some experts think that it actually takes many more colonoscopies to become independently competent. For example, Spier et al. [17] studied performance by 11 GI fellows and concluded that 500 colonoscopies were required to ensure reliable ( $\geq 90 \%$ ) independent colonoscopy completion rates. Almost all gastroenterology fellows and colorectal surgery trainees far exceed the minimal number of colonoscopies required during their training and many would exceed the 500 number. In marked contrast, the ACGME requires general surgery training programs "to document competence" in endoscopy but requires a minimum of only 50 colonoscopies be completed during residency. Despite this low number, some general surgery programs have difficulty meeting the minimal requirement for their trainees [18]. In its position statement, the American Academy of Family Physicians states that colonoscopy is "within the scope of family medicine" and that "the standard of 50 cases as the primary operator be used as a basis for determination of basic competency" [19] but few family practice training programs include formal colonoscopic training. The skeptic might argue that the higher training requirements for gastroenterology fellows and colorectal surgeons is part of a turf protection strategy to discourage other specialists from performing financially rewarding endoscopic procedures, however the outcome data reviewed above belies that view. In fact, it is hardly surprising that training and experience would be a major determinant of colonoscopy quality as it is for many other specialized procedures.

One approach to improving colonoscopy quality would be to recommend that it be done only by gastroenterologists and colorectal surgeons, but this, in our opinion, would be the wrong approach; it would be seriously divisive, it would be justifiably viewed as turf-protective, it would lead to a severe shortage of colonoscopy capacity in the US, and it would not deal with the substantial residual variability in colonoscopy quality among gastroenterologists [4] and colorectal surgeons. Despite the major differences in training requirements among specialties, they are all in agreement that competency in procedures cannot be defined solely by fulfilling minimal quotas, but must be directly assessed by the training program. Proposed parameters for colonoscopy competence include demonstration of adequate independent completion rates (>90\%), withdrawal times (longer than 6-10 min), adenoma detection rates $(\geq 15$ and $25 \%$ for screening exams in women and men, respectively), and demonstrated knowledge of recommended surveillance intervals. Even these minimal requirements are not currently measured or reported in a standard manner by training programs. It is past time for a collaborative effort among all the relevant specialties to agree upon standard colonoscopy quality measures, to develop standard approaches to quality assessment and documentation of competence, and to hold colonoscopists of all specialties to the same high-quality standards. One such collaboration among the major organizations representing gastroenterologists, surgeons, and primary care specialists is being coordinated through the National Colorectal Cancer Roundtable [20], an organization co-founded by the American Cancer Society and the Center for Disease Control and Prevention. In our opinion, such efforts should be both applauded and supported. Patients and those who reimburse endoscopic services deserve, and should demand, assurance of quality. It will be far better for the relevant specialties to develop and implement quality standards than to have them imposed by others.

Colonoscopy is indeed the best test we have to prevent colorectal cancer despite any current variability in quality. As we continue to define patient, system, and 
endoscopist-specific characteristics that are associated with high-quality procedures, it is our responsibility to incorporate these findings into improved training and continuing medical education for all endoscopists.

\section{References}

1. Winawer SJ, Zauber AG, Ho MN, et al. Prevention of colorectal cancer by colonoscopic polypectomy. The National Polyp Study Workgroup. N Engl J Med. 1993;329:1977-1981.

2. BRFSS-CDC's Behavioral Risk Factor Survey Service, Prevalence and Trends Data. http://apps.nccd.cdc.gov/BRFSS/page. asp?cat $=\mathrm{CC} \& \mathrm{yr}=2010 \&$ state $=\mathrm{All} \# \mathrm{CC}$.

3. Martínez ME, Baron JA, Lieberman DA, et al. A pooled analysis of advanced colorectal neoplasia diagnoses after colonoscopic polypectomy. Gastroenterology. 2009;136:832-841.

4. Rex DK. Maximizing detection of adenomas and cancers during colonoscopy. Am J Gastroenterol. 2006;101:2866-2877.

5. Lieberman DA, Faigel DO, Logan JR, et al. Assessment of the quality of colonoscopy reports: results from a multicenter consortium. Gastrointest Endoscopy. 2009;69:645-653.

6. Kaminski MF, Regula J, Kraszewska E, Polkowski M, Wojciechowska U, Didkowska J, Zwierko M, Rupinski M, Nowacki MP, Butruk E. Quality indicators for colonoscopy and the risk of interval cancer. $N$ Engl J Med. 2010;362:1795-1803.

7. Chen SC, Rex DK. Endoscopist can be more powerful than age and male gender in predicting adenoma detection at colonoscopy. Am J Gastroenterol. 2007;102:856-861.

8. Brenner H, Chang-Claude J, Seiler CM, Rickert A, Hoffmeister M. Protection from colorectal cancer after colonoscopy: a population-based, case-controlled study. Ann Intern Med. 2011; 154:22-30.

9. Lakoff J, Paszat LF, Saskin R, Rabeneck L. Risk of developing proximal versus distal colorectal cancer after negative colonoscopy: a population-based study. Clin Gastroenterol Hepatol. 2008;6:1117-1121.
10. Rex DK, Rahmani EY, Haseman JH, Lemmel GT, Kaster S, Buckley JS. Relative sensitivity of colonoscopy and barium enema for detection of colorectal cancer in clinical practice. Gastroenterology. 1997;112:17-23.

11. Singh H, Nugent Z, Mahmud SM, Demers AA, Bernstein CN. Predictors of colorectal cancer after negative colonoscopy: a population-based study. Am J Gastroenterol. 2010;105:663-673.

12. Rabeneck L, Paszat LF, Saskin R. Endoscopist specialty is associated with incident colorectal cancer after a negative colonoscopy. Clin Gastroenterol Hepatol. 2010;8:275-279.

13. Baxter NN, Sutradhar R, Forbes SS, Paszat LF, Saskin R, Rabeneck L. Analysis of administrative data finds endoscopist quality measures associated with post-colonoscopy colorectal cancer. Gastroenterology. 2011;140:65-72.

14. Singh A, Kuo Y-F, Riall TS, Raju GS, Goodwin JS. Predictors of colorectal cancer following a negative colonoscopy in the Medicare population. Dig Dis Sci. (Epub ahead of print). doi: 10.1007/s10620-011-1788-6.

15. Pabby A, Schoen RE, Weissfeld JL, et al. Analysis of colorectal cancer occurrence during surveillance colonoscopy in the dietary Polyp Prevention Trial. Gastrointest Endosc. 2005;61:385-391.

16. ACGME. ACGME program requirements for fellowship education in the subspecialties of internal medicine. ACGME program requirements for general surgery resident trainees in endoscopic procedures.

17. Spier BJ, Benson M, Pfau PR, Nelligan G, Lucey MR, Gaumnitz EA. Colonoscopy training in gastroenterology fellowships: determining competence. Gastrointest Endosc. 2010;71:319-324.

18. Subhas G, Gupta A, Mittal VJ. Necessity for improvement in endoscopy training during surgical residency. Am J Surg. 2010;199:331-335.

19. Colonoscopy (Position Paper)—Policy \& Advocacy-American Academy of Family Physicians. Home Page-American Academy of Family Physicians. 2998. Web. 26 June 2011. http://www. aafp.org/online/en/home/policy/policies/c/colonoscopyposition paper.html.

20. National Colorectal Cancer Roundtable. http://nccrt.org/. 